\title{
Change of the airway space in mandibular prognathism after bimaxillary surgery involving maxillary posterior impaction
}

\author{
Woo-Young Lee, Young-Wook Park, Kwang-Jun Kwon and Seong-Gon Kim
}

\begin{abstract}
Background: The purpose of this retrospective study was to develop a two- and three-dimensional analysis of the airway using cone-beam computed tomography $(\mathrm{CBCT})$ and to determine whether the airway space would be changed in mandibular prognathism after bimaxillary surgery involving maxillary posterior impaction.

Methods: Patients requiring orthognathic surgery from 2012 to 2014 were recruited for this study. CBCT scans were obtained at three points: preoperatively (T0), immediate postoperatively (T1), and after 6 months postoperatively (T2). The nasopharynx, oropharynx, and hypopharynx were measured on the CBCT scan for each patient in a repeatable manner. With the midsagittal plane, linear measurements in the middle of each were obtained. For the CBCT, volumetric measurements of each and total airway were obtained.
\end{abstract}

Results: A total of 22 consecutive patients (11 men and 11 women) were included in the present study. The total volume was significantly reduced $(p<.001)$. However, the change of the diameter and volume of the nasopharynx was not statistically significant ( $p=.160, p=.137$, respectively). In the oropharynx, the change of both the diameter and volume showed statistical significance between preoperatively and immediate postoperatively $(p<.001, p=.001$, respectively) and also preoperatively and after 6 months postoperatively ( $p=.001, p=.010$, respectively). In the hypopharynx, the change of both the diameter and volume showed statistical significance between preoperatively and immediate postoperatively $(p=.001, p<.001$, respectively) and also preoperatively and after 6 months postoperatively $(p=.001, p<.001$, respectively).

Conclusions: The bimaxillary surgery involving maxillary posterior impaction can reduce the volume of airway in the patients of mandibular prognathism. Although total airway volume was reduced significantly, the changes in the volume and diameter of the nasopharynx were not statistically significant. The maxillary posterior impaction affects on the nasopharyngeal airway minimally.

Keywords: Orthognathic surgery, Airway management, Cone-beam computed tomography

\section{Background}

Typically, class III malocclusion patients represent a combination of facial malformations in the skeletal and dental alveolar bone [1]. Most of these patients can exhibit mandibular prognathism and maxillary retrognathism. For the establishment of the patient's optimal occlusion and profile, it is necessary to perform orthognathic surgery, especially bilateral sagittal split ramus osteotomy (SSRO) or vertical ramus osteotomy (VRO)

\footnotetext{
*Correspondence: ywpark@gwnu.ac.kr

Department of Oral and Maxillofacial Surgery, College of Dentistry, Gangneung-Wonju National University, 7 Jukheon-gil, Gangneung, Gangwondo 210-702, South Korea
}

[2]. However, some patients required both maxillary and mandibular surgery, the so-called bimaxillary orthognathic surgery [3]. Clockwise rotation of the maxilla (posterior impaction) can achieve correction of acute nasolabial angle and stabilization of the occlusal plane.

But this surgical movement of the maxilla may reduce the volume of airway space [4]. In the case of the class III malocclusion patients performed with orthognathic surgery, it can change the position of the hyoid bone and tongue, and the base of the tongue moves to the posterior, which will increase the contact surface between the soft palate and tongue $[5,6]$. As a result, the pharyngeal airway space 
is narrowed [7]. Up to date, there are many reports of airway reduction in mandibular set back surgery but rare in maxillary posterior impaction.

In these patients, cone-beam computed tomography (CBCT) has been attracting attention for the three-dimensional assessment of the airway, an important role in the process of diagnosis in place of the conventional CT $[8,9]$. $\mathrm{CBCT}$ is equipped with a fast scanning equipment and low exposure to radiation as compared to conventional CT $[9,10]$. As it can observe on various directions for evaluation of three-dimensional airway reconstruction, it can be suitable for use as a measuring apparatus for a change in the airway between preoperative and postoperative procedure [11].

The purpose of this retrospective study was to develop a two and three-dimensional analysis of the airway using $\mathrm{CBCT}$ and to determine whether the difference in the airway volume would be changed with posterior impaction of maxilla in orthognathic surgery.

\section{Methods}

\section{Patient analysis}

From January 2012 to January 2014, a selected group of 22 patients with skeletal class III malocclusion who have complete records were chosen (Tables 1 and 2). Patients with systemic surgical contraindications were excluded from the study. The operations have been performed by the experienced surgeon, and anesthesia was administered by an experienced anesthetist. After surgery, most patients remained in the hospital for 7 days. A standard regimen of antibiotics was administered for 7 days according to clinical conditions. All patients were admitted 1 day before the surgery. A prophylactic antibiotic treatment (augmentin or cefazolin) was routinely given with the induction of anesthesia. NSAID (ketorolac tromethamine) was given for postoperative analgesia. Corticosteroid was given for 3 days via tapering process. All patients were done with intermaxillary fixation by elastic rubber to fit in occlusal stent. When they would be discharged, intermaxillary fixation was removed, and rubber guiding was done.

\section{Radiographic analysis}

The radiologic information was taken by cone-beam computed tomography (Alphard, Asahi Roentgen Co., Kyoto, Japan) which was used in the Gangneung-Wonju National University dental hospital, Department of Oral and Maxillofacial Radiology for patient radiographic

Table 1 Patients information

\begin{tabular}{|c|c|c|c|c|c|c|c|}
\hline Patient no. & Age (years) & Sex & Mx post. impaction ${ }^{a}(\mathrm{~mm})$ & $\begin{array}{l}\text { Fixed reference } \\
\text { point }\end{array}$ & $\begin{array}{l}\text { A-P movement } \\
\text { of maxilla }(\mathrm{mm})\end{array}$ & Mn set back (mm) & Genioplasty (mm) \\
\hline 1 & 22 & M & 5 & ANS & - & 12 & - \\
\hline 2 & 23 & M & 2.5 & ANS & - & 11 & - \\
\hline 3 & 19 & M & 5 & ANS & - & 13 & - \\
\hline 4 & 20 & M & 2 & ANS & - & 9.5 & Reduction, 4 \\
\hline 5 & 21 & M & 3 & ANS & - & 15 & Advancement, 4 \\
\hline 6 & 21 & M & 6 & Incisor tip & Advancement, 1 & 13 & Advancement, 6 \\
\hline 7 & 22 & M & 3 & ANS & - & 10 & Advancement, 6 \\
\hline 8 & 22 & M & 4 & ANS & - & 10.5 & Advancement, 4 \\
\hline 9 & 24 & M & 3.5 & ANS & - & 9 & Reduction, 4 \\
\hline 10 & 20 & M & 5 & ANS & - & 9 & - \\
\hline 11 & 23 & M & 5 & ANS & - & 14.5 & - \\
\hline 12 & 17 & $\mathrm{~F}$ & 2 & ANS & - & 5 & - \\
\hline 13 & 26 & $\mathrm{~F}$ & 5 & ANS & - & 10 & - \\
\hline 14 & 19 & $\mathrm{~F}$ & 3 & ANS & - & 9 & Reduction, 4 \\
\hline 15 & 32 & $\mathrm{~F}$ & 5 & ANS & - & 7.5 & - \\
\hline 16 & 20 & $\mathrm{~F}$ & 3.5 & ANS & - & 12 & Advancement, 4 \\
\hline 17 & 20 & $\mathrm{~F}$ & 5 & ANS & - & 8 & Advancement, 4 \\
\hline 18 & 19 & $\mathrm{~F}$ & 4 & ANS & - & 15 & Advancement, 4 \\
\hline 19 & 20 & $\mathrm{~F}$ & 6 & ANS & - & 7 & - \\
\hline 20 & 18 & $\mathrm{~F}$ & 3 & ANS & - & 13 & Reduction, 4 \\
\hline 21 & 23 & $\mathrm{~F}$ & 5 & ANS & - & 6.5 & - \\
\hline 22 & 33 & $\mathrm{~F}$ & 5 & ANS & - & 5.5 & - \\
\hline
\end{tabular}


Table 2 Sample mean

\begin{tabular}{llll}
\hline & Male $(n=11)$ & Female $(n=11)$ & $P$ value \\
\hline Age (SD) & $21.54(1.50)$ & $22.45(5.53)$ & .609 \\
Mn. set back (SD) & $10.83(1.91)$ & $9.22(2.76)$ & .130 \\
Post. impaction (SD) & $3.72(1.36)$ & $3.77(1.32)$ & .938 \\
\hline
\end{tabular}

Mandibular set back and posterior impaction are expressed by millimeters. The $t$ test was used, and $P$ values $<.05$ are statistically significant

Abbreviations: Mn. mandibular, Post. posterior, SD standard deviation

evaluation. The subjects were positioned with the Frankfort horizontal plane parallel to the floor and instructed to maintain maximum intercuspation with the tongue touching the palate and to avoid swallowing during the scanning period. The three-dimensional image reconstruction was performed to use of the software (Xelis dental, Infinitt Health Care, Seoul, Korea).

\section{Evaluation of airway change}

CBCT scans were obtained at three points: preoperatively (T0), immediate postoperatively (T1), and after 6 months postoperatively (T2). The nasopharynx, oropharynx, and hypopharynx were measured on the CBCT scan for each patient in a repeatable manner at each point (Table 3.). But in this study, lower margin of nasopharynx and upper margin of oropharynx were changed, because maxillary posterior impaction could change the height of posterior nasal spine (PNS). So, we divided the nasopharynx and oropharynx by the plane parallel to Frankfort horizontal plane $(\mathrm{FH})$ passing through the anterior nasal spine (ANS).

Three linear measurements and volumetric measurements were made for each image, respectively. Initially, the examiner measured the airway's anteroposterior length in the midsagittal plane slice at three levels
(Fig. 1): anterior nasal spine (the inferior border of nasopharynx), most anteroinferior point of second cervical spine (the inferior border of oropharynx), and the base of epiglottis (the inferior border of hypopharynx). The airway space within the anatomic borders was isolated, and the volume of the each airway was measured after exposing only the airway part (Fig. 2).

\section{Statistics}

The paired $t$ test was used for tests of significance in patients preoperatively ( $\mathrm{T} 0$ ), immediate postoperatively (T1), and after 6 months postoperatively (T2). Results are expressed as mean \pm SD , and statistical significance was accepted at $P<.05$. Statistical analyses were performed with SPSS for Windows, version 19.0 (SPSS Inc., Chicago, USA).

\section{Results}

The patient information data are summarized in Tables 1 and 2. A total of 22 consecutive patients (11 males and 11 females) were included in the present study, with an age range of 17 to 33 years. The average ages of men and women patients were 21.54 and 22.45 , respectively. All patients received surgery for posterior impaction of the maxilla and mandibular set back surgery. The average movement of the maxillary posterior impaction is $3.72 \mathrm{~mm}$ in male patients $(\mathrm{SD}=1.36)$ and $3.77 \mathrm{~mm}$ in female patients $(\mathrm{SD}=1.32)$, and the average movement of mandibular set back is $10.83 \mathrm{~mm}$ in male $(\mathrm{SD}=1.91)$ and $9.22 \mathrm{~mm}$ in female. There was no significance between male and female.

The linear measurements are summarized in Table 4. The change of diameter in the nasopharynx was not statistically significant between preoperatively and immediate postoperatively $(p=.160)$. It did not show a statistically

Table 3 Anatomical limits of the airway

\begin{tabular}{lll}
\hline Region & Limit & Anatomical \\
\hline Nasopharynx & Anterior & Frontal plane perpendicular to FH passing through PNS \\
& Posterior & Soft tissue contour of the pharyngeal wall \\
Upper & Soft tissue contour of the pharyngeal wall \\
Lower & Plane parallel to FH passing through ANS and extended to the posterior wall of the pharynx \\
Oropharynx & Frterior & Frontal plane perpendicular to FH passing through PNS \\
& Posterior & Soft tissue contour of the pharyngeal wall \\
Upper & Plane parallel to FH passing through ANS and extended to the posterior wall of the pharynx \\
Hypopharynx & Power & Plane parallel to FH plane passing through C2ai \\
& Posterior & Soft tissue contour of the pharyngeal wall \\
Upper & Plane parallel to FH plane passing through C2ai
\end{tabular}




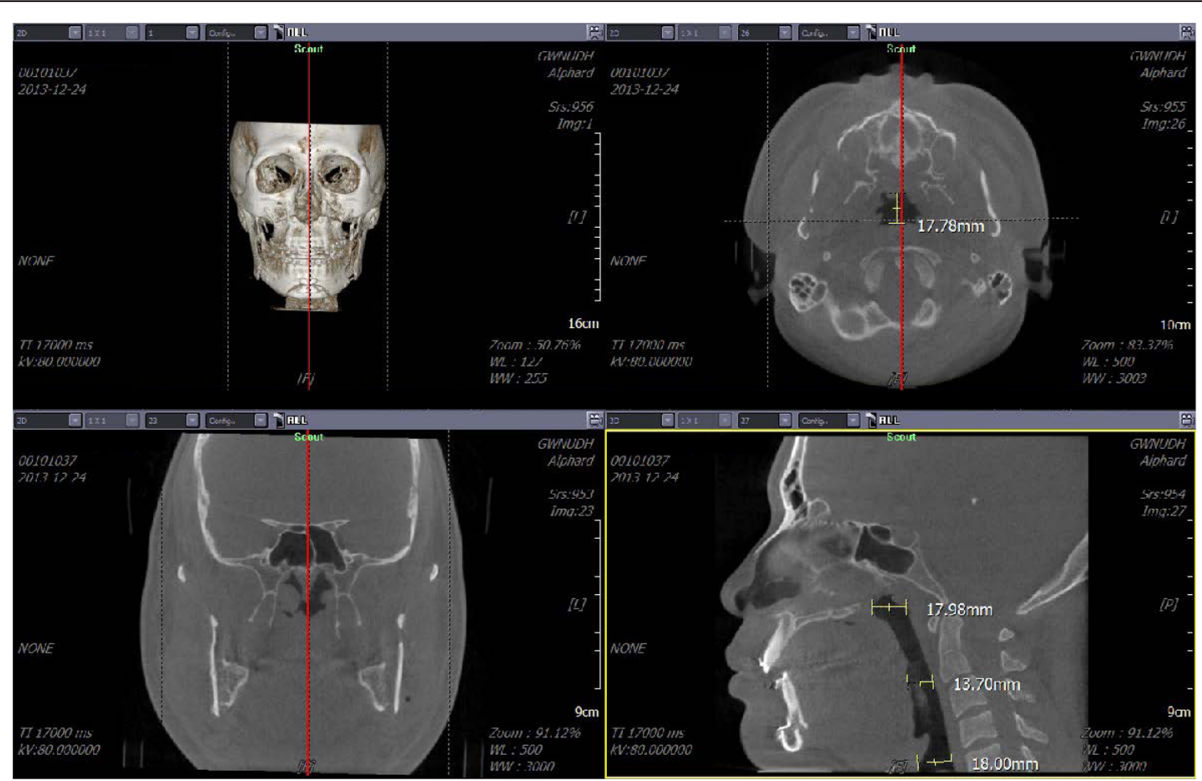

Fig. 1 Measuring the length of the airway

significant difference in immediate postoperatively and after 6 months postoperatively $(p=.556)$. Also, there was no statistical significance in the difference between preoperatively and after 6 months postoperatively $(p=.339)$. The change of diameter in the oropharynx was statistically significant between preoperatively and immediate postoperatively $(p<.001)$. It did not show a statistically significant difference in immediate postoperatively and after 6 months postoperatively ( $p=.253$ ). However, it presented statistically significant in the difference between preoperatively and after 6 months postoperatively $(p=.001)$. The change of diameter in the hypopharynx was statistically significant between preoperatively and immediate postoperatively $(p=.001)$. It did not show a statistically significant difference in the immediate postoperatively and after 6 months postoperatively $(p=.932)$. However, there was statistical significance in the difference between preoperatively and after 6 months postoperatively $(p=.001)$.

The volumetric measurements are summarized in Table 5. The change of volume in the nasopharynx was not statistically significant between preoperatively and immediate postoperatively $(p=.137)$. It did not show a statistically significant difference in immediate postoperatively and after 6 months postoperatively $(p=.405)$.

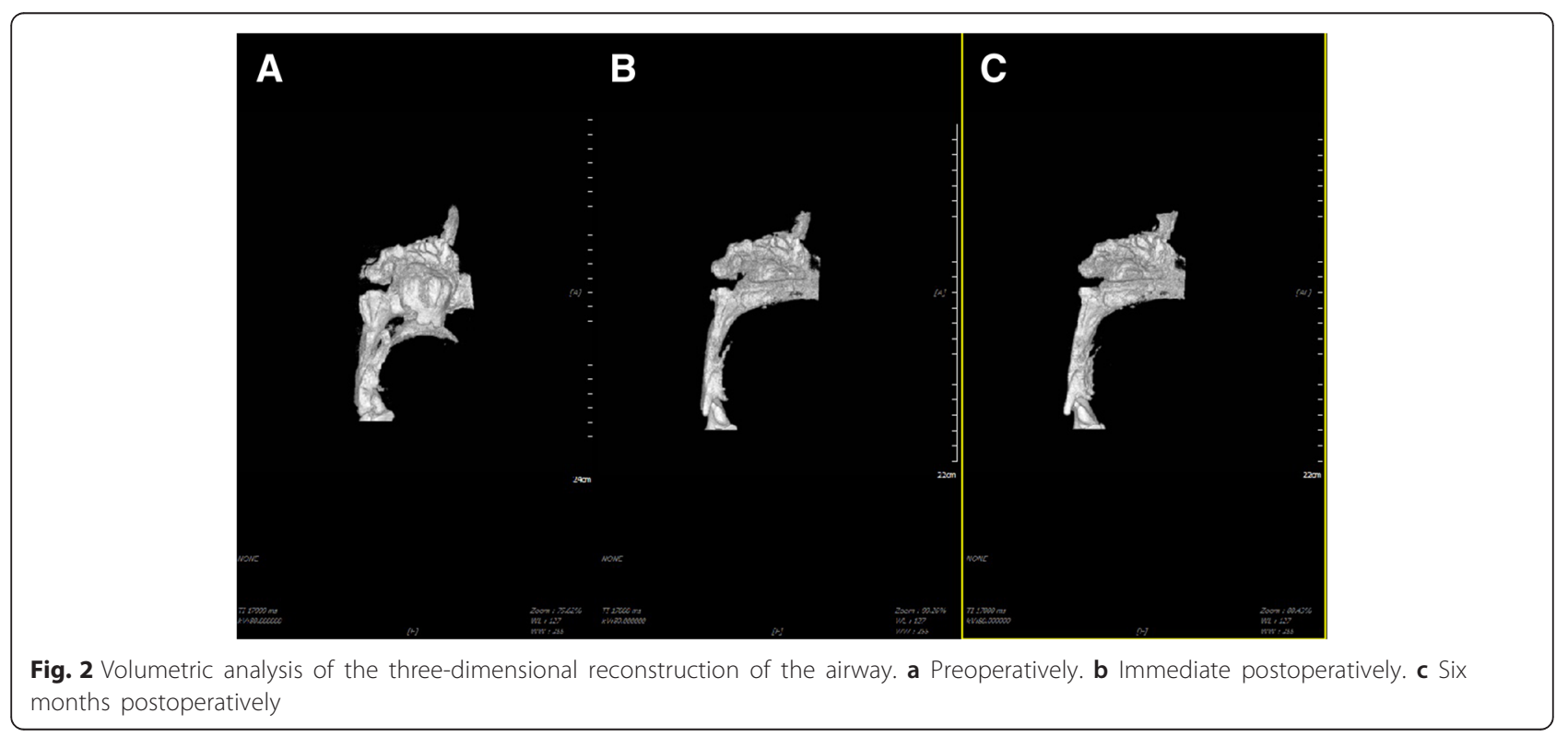


Table 4 Comparison of the linear measurement on preoperatively (T0), immediate postoperatively (T1), and after 6 months postoperatively (T2)

\begin{tabular}{lllllll}
\hline$n=22$ & T0 & T1 & T2 & & $P$ value \\
\cline { 5 - 7 } & Mean (SD) percentage & Mean (SD) percentage & Mean (SD) percentage & T0-T1 & T1-T2 & T0-T2 \\
\hline Nasopharynx & $19.74(3.77) 100 \%$ & $19.15(3.24) 97.0 \%$ & $19.43(3.89) 98.4 \%$ & .160 & .556 & .339 \\
Oropharynx & $17.54(5.07) 100 \%$ & $13.58(4.58) 77.4 \%$ & $14.33(4.04) 81.7 \%$ & $<.001$ & .253 & .001 \\
Hypopharynx & $18.21(6.17) 100 \%$ & $14.86(4.20) 81.6 \%$ & $14.81(3.94) 81.3 \%$ & .001 & .932 & .001
\end{tabular}

Linear measurements are expressed by millimeters. The preoperative state (T0) was defined as $100 \%$. The paired $t$ test was used, and $P$ values $<.05$ are statistically significant

Abbreviations: $T 0$ preoperatively, $T 1$ immediate postoperatively, $T 2$ after 6 months postoperatively, $S D$ standard deviation

Also, there was no statistical significance in the difference between preoperatively and after 6 months postoperatively $(p=.358)$. The change of volume in the oropharynx was statistically significant between preoperatively and immediate postoperatively $(p<.001)$. It did not show a statistically significant difference in immediate postoperatively and after 6 months postoperatively $(p=.361)$. However, it presented statistical significance in the difference between preoperatively and after 6 months postoperatively $(p<.001)$. The change of volume in the hypopharynx was statistically significant between preoperatively and immediate postoperatively $(p=.010)$. It did not show a statistically significant difference in immediate postoperatively and after 6 months postoperatively $(p=.836)$. However, there was statistical significance in the difference between preoperatively and after 6 months postoperatively $(p=.007)$. Total volume decreased significantly preoperatively and after 6 months postoperatively compared preoperatively $(p<.001$, both).

Comparisons of the change in total volume between male and female are summarized in Table 6. Female patients showed the narrower airway after surgery compared to male patients. There was significant difference between immediate postoperatively and after 6 months postoperatively $(p=.021)$.

\section{Discussion}

In the patients of skeletal class III malocclusion who were treated with the surgical procedure, it causes a change in the position of the tongue and hyoid bone and the tongue base moved to the posterior [12, 13]. As a result, the contact surface would increase between the soft palate and the tongue and consequently decrease the pharyngeal airway space [14]. This mechanism brings about morphologic change of oro-pharyngeal area and causes problems such as sleep apnea and snoring [1]. Riley et al. reported that if the pharyngeal airway space is less than $11 \mathrm{~mm}$, the distance from the mandibular plane to the hyoid bone is more than $15 \mathrm{~mm}$, it can cause sleep apnea or snoring [15]. Partinen et al. reported that if the pharyngeal airway space on the tongue base is less than $5 \mathrm{~mm}$ and the distance from the mandibular plane to the hyoid bone is more than $24 \mathrm{~mm}$, it can bring about severe respiratory disorder [16].

Evaluation of the airway through the $\mathrm{CBCT}$ is reliable. In the airway analysis, many studies have used $\mathrm{CBCT}$ than conventional CT $[17,18]$. CBCT is equipped with fast scanning equipment and low exposure to radiation as compared to conventional CT [8-10]. Mattos CT et al. reported that CBCT evaluation of the upper airway was reliable. In the study, the authors evaluated linear and volumetric measurements by CBCT [19]. Vizzotto MB et al. reported that both lateral cephalogram and $3 \mathrm{D}$ reconstruction by $\mathrm{CBCT}$ were suitable for evaluation of airway space [20]. In our study, there were minimal linear difference on midsagittal plane and axial plane. And patient position was reproducible. So, CBCT evaluation of this study was reliable.

In this study, we compared the changes in airway volume and diameter of the patients who underwent maxillary posterior impaction surgery. All patients were accompanied mandibular set back surgery via SSRO or

Table 5 Comparison of the volumetric measurement on preoperatively (T0), immediate postoperatively (T1), and after 6 months postoperatively (T2)

\begin{tabular}{lllllll}
\hline$n=22$ & T0 & T1 & T2 & \multicolumn{2}{c}{$P$ value } \\
\cline { 3 - 7 } & Mean (SD) percentage & Mean (SD) percentage & Mean (SD) percentage & T0-T1 & T1-T2 & T0-T2 \\
\hline Nasopharynx & $5363.45(1895.90) 100 \%$ & $5013.05(1562.34) 93.5 \%$ & $5214.30(1892.05) 97.2 \%$ & .137 & .405 & .358 \\
Oropharynx & $17,833.09(9130.96) 100 \%$ & $10,989.30(6776.01) 61.6 \%$ & $11,860.33(6187.34) 66.5 \%$ & $<.001$ & .361 & $<.001$ \\
Hypopharynx & $7175.34(5344.89) 100 \%$ & $4635.66(2513.35) 64.6 \%$ & $4568.04(2324.86) 63.7 \%$ & .010 & .836 & .007 \\
Total & $30,371.88(13,547.62) 100 \%$ & $20,638.01(9585.39) 68.0 \%$ & $21,642.67(9164.16) 71.3 \%$ & $<.001$ & .445 & $<.001$ \\
\hline
\end{tabular}

Volumetric measurements are expressed by cubic millimeters. The preoperative state (T0) was defined as $100 \%$. The paired $t$ test was used, and $P$ values $<.05$ are statistically significant.

Abbreviations: TO preoperatively, $T 1$ immediate postoperatively, $T 2$ after 6 months postoperatively, SD standard deviation 
Table 6 Comparison of the change in total volume between male and female

\begin{tabular}{lllllll}
\hline & T0-T1 & $P$ value & T1-T2 & $P$ value & T0-T2 & $P$ value \\
& Mean (SD) & & Mean (SD) & & Mean (SD) \\
\hline Male $(n=11)$ & $6733.05(5415.95)$ & .112 & $2407.24(1760.56)$ & .021 & $5925.27(4242.12)$ \\
Female $(n=11)$ & $13,169.83(9998.66)$ & & $6883.35(4202.39)$ & & $11,646.18(9638.95)$ \\
\hline
\end{tabular}

Volumetric measurements are expressed by cubic millimeters. The independent $t$ test was used, and $P$ values $<.05$ are statistically significant Abbreviations: TO preoperatively, $T 1$ immediate postoperatively, $T 2$ after 6 months postoperatively, SD standard deviation

VRO. Although total airway volume was reduced significantly, the changes in volume and diameter of nasopharynx were not statistically significant. The maxillary posterior impaction affected minimally on the nasopharyngeal airway. The average movement of $4 \mathrm{~mm}$ is very small so that it could not result in airway change. However, oropharynx and hypopharynx showed statistically significant differences between preoperatively and postoperatively. In the author's opinion, this was due to mandibular set back movement. The amount of movement of the mandible is usually larger than that of the maxilla. And this mandibular movement is granted a direct effect on the position of the tongue and hyoid bone. Therefore, the diameter and volume of the oropharynx and the hypopharynx are reduced, and total airway volume was also decreased.

Female patients showed the narrower airway after surgery compared to male patients. The reduction of the airway was related not only to the position of the tongue and hyoid bone but also to the edema of the respiratory mucosa. Articles which analyzed the changes in the edema by gender are rare. It was believed that this was the result of the difference in the hormone between the male and female. More research is needed.

Snoring occurred in one patient who underwent both SSRO and maxillary posterior impaction. She had narrow airway before the surgery. Comparing to preoperative CBCT measurements, we could find reduction of the airway, and in the postoperative 6-month $\mathrm{CBCT}$ evaluation, the airway did not returned to the preoperative. However, in the postoperative 6-month $\mathrm{CBCT}$ evaluation, the patient did not complain about her snoring anymore (Fig. 3a). Another patient had narrower airway than her before surgery and in postoperative CBCT. However, she did not present snoring and any other airway compromises (Fig. 3b). Therefore, snoring did not always occur because of airway reduction due to orthognathic surgery [21]. There are several factors correlated with snoring such as head posture, respiratory habit, and tongue position $[1,3,13,16]$. However, orthognathic surgery is not directly related to snoring and more research is needed.

There are many reports of airway reduction after orthognathic surgery [4], and some patients appear to have respiratory disorder or snoring [5, 12, 22]. If the surgeons understand the volume and width change of the airway between preoperative and postoperative, respiratory complications such as sleep apnea and snoring can be prevented [23]. Withal, if the evaluation of upper airway change in maxillary posterior impaction is possible, the surgeons would perform additional surgical procedures to prevent nasal airway problems [21].

There are many articles dealing with airway change after orthognathic surgery. Pereira-Filho VA et al. evaluated the correlation of maxillary advancement surgery and airway change. In this study, maxillary advancement surgery could dilate the volumes of nasopharynx and oropharynx but not hypopharynx [22]. R. Foltan et al. reported that maxillary advancement surgery could improve the respiratory condition of the upper airway [23]. But the relationship between maxillary posterior impaction surgery and upper airway change has not had been

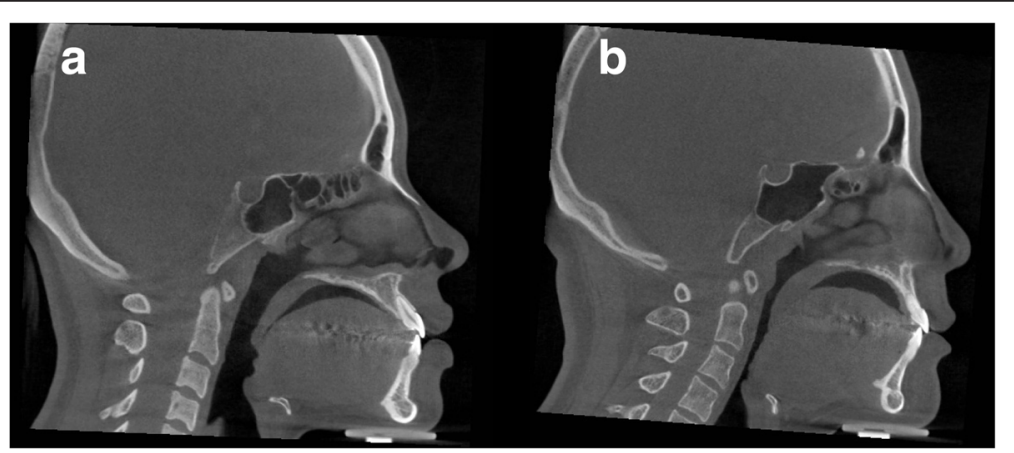

Fig. 3 Sagittal plane view after 6 months postoperatively. The airway of patient $\mathbf{b}$ was narrower than that of $\mathbf{a}$. However, patient $\mathbf{a}$ showed snorting, but not $\mathbf{b}$ 
sufficient research. In the total volume of the airway, Lee $\mathrm{Y}$ et al. reported that bimaxillary orthognathic surgery for the correction of class III malocclusion affected the morphology by increasing the upper part and decreasing the lower part of the airway, but not the total volume [24]. However, Choi SK et al. reported that mandibular set back surgery was significantly associated with postoperative reduction of airway space [25]. In this study, we found that bimaxillary surgery involving maxillary posterior impaction could highly affect airway space of mandibular prognathism patients. So, the airway change due to bimaxillary surgery should be considered.

\section{Conclusions}

The bimaxillary surgery involving maxillary posterior impaction can reduce the volume of airway of mandibular prognathism patients. Although total airway volume was reduced significantly, the changes in volume and diameter of nasopharynx were not statistically significant. The maxillary posterior impaction affects the nasopharyngeal airway, minimally.

\section{Competing interests}

The authors declare that they have no competing interests.

\section{Authors' contributions}

WYL drafted the manuscript. YWP performed the surgery in all cases. KJK performed the general anesthesia in all cases. SGK participated in the proofreading of the manuscript. All authors read and approved the final manuscript.

\section{Acknowledgements}

This work was supported by the Scientific Research (SR1401) of the Gangneung-Wonju National University Dental Hospital.

Received: 17 February 2016 Accepted: 19 May 2016

Published online: 07 June 2016

\section{References}

1. Gokce S, Gorgulu S, Gokce H et al (2012) Changes in posterior airway space, pulmonary function and sleep quality, following bimaxillary orthognathic surgery. Int J Oral Maxillofac Surg 41(7):820-829

2. Chen F, Terada K, Hua Y, Saito I (2007) Effects of bimaxillary surgery and mandibular setback surgery on phanyngeal airway measurements in patients with class III skeletal deformities. Am J Orthod Dentofacial Orthop 131(3):372-377

3. Becker OE, Avelar RL, Göelzer JG, Do Nascimento Dolzan A, Júnior OLH, De Oliveira RB (2012) Pharyngeal airway changes in class III patients treated with double jaw orthognathic surgery-maxillary advancement and mandibular setback. J Oral Maxillofac Surg 70(11):e639-47

4. Wolford LM, Perez D, Stevao E, Perez E (2012) Airway space changes after nasopharyngeal adenoidectomy in conjunction with Le Fort I osteotomy. J Oral Maxillofac Surg 70(3):665-671

5. De Souza CA, Magro Filho O, Garcia I, Araujo P, Nogueira R (2012) Cephalometric and three-dimensional assessment of superior posterior airway space after maxillomandibular advancement. Int J Oral Maxillofac Surg 41(9):1102-1111

6. Mattos C, Vilani G, Sant'Anna E, Ruellas A, Maia L (2011) Effects of orthognathic surgery on oropharyngeal airway: a meta-analysis. Int J Oral Maxillofac Surg 40(12):1347-1356

7. Foltán R, Hoffmannová J, Pavlíková G et al (2011) The influence of orthognathic surgery on ventilation during sleep. Int J Oral Maxillofac Surg 40(2):146-149

8. Guijarro-Martínez R, Swennen G (2013) Three-dimensional cone beam computed tomography definition of the anatomical subregions of the upper airway: a validation study. Int J Oral Maxillofac Surg 42(9):1140-1149
9. Guijarro-Martinez R, Swennen G (2011) Cone-beam computerized tomography imaging and analysis of the upper airway: a systematic review of the literature. Int J Oral Maxillofac Surg 40(11):1227-1237

10. Souza KRS, Oltramari-Navarro PVP, Navarro RL, Conti ACCF, Almeida MR (2013) Reliability of a method to conduct upper airway analysis in cone-beam computed tomography. Braz Oral Res 27(1):48-54

11. Stratemann S, Huang JC, Maki K, Hatcher D, Miller AJ (2011) Three-dimensional analysis of the airway with cone-beam computed tomography. Am J Orthod Dentofacial Orthop 140(5):607-615

12. Demetriades N, Chang DJ, Laskarides C, Papageorge M (2010) Effects of mandibular retropositioning, with or without maxillary advancement, on the oro-naso-pharyngeal airway and development of sleep-related breathing disorders. J Oral Maxillofac Surg 68(10):2431-2436

13. Park J-W, Kim N-K, Kim J-W, Kim M-J, Chang Y-I (2010) Volumetric, planar, and linear analyses of pharyngeal airway change on computed tomography and cephalometry after mandibular setback surgery. Am J Orthod Dentofacial Orthop 138(3):292-299

14. Kim M-A, Kim B-R, Choi J-Y, Youn J-K, Kim Y-JR, Park Y-H (2013) Threedimensional changes of the hyoid bone and airway volumes related to its relationship with horizontal anatomic planes after bimaxillary surgery in skeletal class III patients. Angle Orthod 83(4):623-629

15. Riley RW, Powell NB, Guilleminault C (1990) Maxillary, mandibular, and hyoid advancement for treatment of obstructive sleep apnea: a review of 40 patients. J Oral Maxillofac Surg 48(1):20-26

16. Partinen M, Guilleminault C, Quera-Salva M, Jamieson A (1988) Obstructive sleep apnea and cephalometric roentgenograms. The role of anatomic upper airway abnormalities in the definition of abnormal breathing during sleep. Chest 93(6):1199-1205

17. Sears CR, Miller AJ, Chang MK, Huang JC, Lee JS (2011) Comparison of pharyngeal airway changes on plain radiography and cone-beam computed tomography after orthognathic surgery. J Oral Maxillofac Surg 69(11):e385-e394

18. Hernández-Alfaro F, Guijarro-Martínez R, Mareque-Bueno J (2011) Effect of mono-and bimaxillary advancement on pharyngeal airway volume: cone-beam computed tomography evaluation. J Oral Maxillofac Surg 69(11):e395-e400

19. Mattos CT, Cruz CV, Da Matta TCS et al (2014) Reliability of upper airway linear, area, and volumetric measurements in cone-beam computed tomography. Am J Orthod Dentofacial Orthop 145(2):188-197

20. Vizzotto MB, Liedke GS, Delamare EL, Silveira HD, Dutra V, Silveira HE (2012) A comparative study of lateral cephalograms and cone-beam computed tomographic images in upper airway assessment. Eur J Orthod 34(3):390-393

21. Hasebe D, Kobayashi T, Hasegawa M et al (2011) Changes in oropharyngeal airway and respiratory function during sleep after orthognathic surgery in patients with mandibular prognathism. Int J Oral Maxillofac Surg 40(6):584-592

22. Pereira-Filho VA, Castro-Silva LM, De Moraes M, Gabrielli MFR, Campos JADB, Juergens P (2011) Cephalometric evaluation of pharyngeal airway space changes in class III patients undergoing orthognathic surgery. J Oral Maxillofac Surg 69(11):e409-e415

23. Foltán R, Hoffmannová J, Donev F et al (2009) The impact of Le Fort advancement and bilateral sagittal split osteotomy setback on ventilation during sleep. Int J Oral Maxillofac Surg 38(10):1036-1040

24. Lee Y, Chun Y-S, Kang N, Kim M (2012) Volumetric changes in the upper airway after bimaxillary surgery for skeletal class III malocclusions: a case series study using 3-dimensional cone-beam computed tomography. J Oral Maxillofac Surg 70(12):2867-2875

25. Choi S-K, Yoon J-E, Cho J-W, Kim J-W, Kim S-J, Kim M-R (2014) Changes of the airway space and the position of hyoid bone after mandibular set back surgery using bilateral sagittal split ramus osteotomy technique. Maxillofac Plast Reconstr Surg 36:185-191 